\title{
Protective role for club cell secretory protein-16 (CC16) in the development of COPD
}

\author{
Maria E. Laucho-Contreras ${ }^{1,6}$, Francesca Polverino ${ }^{1,2,3,6}$, Kushagra Gupta ${ }^{1}$, \\ Katherine L. Taylor ${ }^{1}$, Emer Kelly ${ }^{1}$, Victor Pinto-Plata ${ }^{1,2}$, Miguel Divo ${ }^{1}$, \\ Naveed Ashfaq ${ }^{1}$, Hans Petersen ${ }^{2}$, Barry Stripp ${ }^{4}$, Aprile L. Pilon ${ }^{5}$, \\ Yohannes Tesfaigzi ${ }^{2}$, Bartolome R. Celli ${ }^{1,2}$ and Caroline A. Owen ${ }^{1,2}$
}

Affiliations: ${ }^{2}$ Pulmonary Division, Brigham and Women's Hospital, Harvard Medical School, Boston, MA, USA. ${ }^{2}$ Lovelace Respiratory Research Institute, Albuquerque, NM, USA. ${ }^{3}$ Pulmonary Division, University of Parma, Parma, Italy. ${ }^{4}$ Regenerative Medicine Institute, Cedars-Sinai Medical Center, Los Angeles, CA, USA. ${ }^{5}$ Clarassance Inc., Rockville, MD, USA. ${ }^{6}$ These authors contributed equally to this manuscript.

Correspondence: Caroline A. Owen, Division of Pulmonary and Critical Care Medicine, Brigham and Women's Hospital, Room 855B, Harvard Institutes of Medicine Building, 77 Avenue Louis Pasteur, Boston, MA 02115, USA. E-mail: cowendarics.bwh.harvard.edu

ABSTRACT Club cell secretory protein-16 (CC16) is the major secreted product of airway club cells, but its role in the pathogenesis of chronic obstructive pulmonary disease (COPD) is unclear. We measured CC16 airway expression in humans with and without COPD and CC16 function in a cigarette smoke (CS)-induced COPD murine model.

Airway CC16 expression was measured in COPD patients, smokers without COPD and non-smokers. We exposed wildtype (WT) and $C C 16^{-1-}$ mice to CS or air for up to 6 months, and measured airway CC16 expression, pulmonary inflammation, alveolar septal cell apoptosis, airspace enlargement, airway mucin 5AC (MUC5AC) expression, small airway remodelling and pulmonary function.

Smokers and COPD patients had reduced airway CC16 immunostaining that decreased with increasing COPD severity. Exposing mice to CS reduced airway CC16 expression. CC16 ${ }^{-/-}$mice had greater CS-induced emphysema, airway remodelling, pulmonary inflammation, alveolar cell apoptosis, airway MUC5AC expression, and more compliant lungs than WT mice. These changes were associated with increased nuclear factor- $\kappa \mathrm{B}(\mathrm{NF}-\kappa \mathrm{B})$ activation in $\mathrm{CC} 16^{-/-}$lungs. $\mathrm{CS}$-induced acute pulmonary changes were reversed by adenoviral-mediated over-expression of CC16.

CC16 protects lungs from CS-induced injury by reducing lung NF- $\kappa \mathrm{B}$ activation. CS-induced airway CC16 deficiency increases CS-induced pulmonary inflammation and injury and likely contributes to the pathogenesis of COPD.

@ERSpublications

Cigarette smoke exposure reduces airway levels of anti-inflammatory CC16 to thereby contribute to the genesis of COPD http://ow.ly/GOMiZ

Editorial comment in Eur Respir J 2015; 45: 1519-1520 [DOI: 10.1183/09031936.00010515].

This article has supplementary material available from erj.ersjournals.com

Received: July 232014 | Accepted after revision: Dec 062014 | First published online: Feb 192015

Support statement: Funding was provided by the Flight Attendant Medical Research Institute (FAMRI CIA 123046), the BWH-LRRI Consortium and the NHLBI (P01 HL114501, P50 HL107165-01, R01 AI111475, R21 HL111835). Funding information for this article has been deposited with FundRef.

Conflict of interest: Disclosures can be found alongside the online version of this article at erj.ersjournals.com

Copyright OERS 2015 


\section{Introduction}

Chronic obstructive pulmonary disease (COPD) is a major cause of morbidity and mortality worldwide [1]. COPD results from a poorly controlled lung inflammatory response to inhaled particles, primarily in cigarette smoke (CS), leading to destruction of the alveolar walls and small airway remodelling [2]. The severity and progression of COPD are graded by the forced expiratory volume in $1 \mathrm{~s}$ (FEV1) [3].

Faster rate of decline in FEV1 in COPD is linked to current smoker status, higher baseline FEV1, low body mass index, the degree of computer tomography-determined emphysema and a history of COPD exacerbations [4-6]. In the Evaluation of COPD Longitudinally to Identify Predictive Surrogate Endpoints (ECLIPSE) study, the only association observed between rate of $\mathrm{FEV}_{1}$ decline and serum levels of various biomarkers was a protective effect associated with higher levels of club cell secretory protein-16 (CC16) [7]. This inverse relationship between serum CC16 levels and FEV1 decline was confirmed in a cohort of mild COPD patients [8].

CC16 is also known as CC10, club cell secretory protein, secretoglobin, family 1A, member 1 (SCGB1A1) and uteroglobin. It is a member of the secretoglobin family of disulphide-bridged dimeric proteins secreted by airway club cells and is the most abundant protein in normal airway secretions. CC16 maintains the homeostasis of the airway epithelium [9], and has anti-inflammatory activities in lungs exposed to ozone, allergens and viruses [10-12]. Plasma CC16 levels are low in cigarette smokers and patients with asthma and obliterative bronchiolitis [13-15]. Plasma CC16 levels increase following smoking cessation [16] and increases in bronchoalveolar lavage (BAL) fluid (BALF) CC16 levels correlate with regression of bronchial dysplasia in former smokers [17]. Although a recent study reported that $C C 16^{-/-}$mice developed similar emphysema as wildtype (WT) mice when exposed to CS [8], there are knowledge gaps about the contributions of CC16 to COPD pathogenesis.

We tested the following hypotheses: 1) airway CC16 expression is reduced in smokers without COPD and COPD patients and, in COPD patients, it correlates inversely with the degree of airflow limitation; 2) airway CC16 levels progressively decrease in WT mice exposed to CS; and 3) when exposed to CS, CC16-deficient $\left(\mathrm{CC} 16^{--}\right)$mice have greater pulmonary inflammation, airspace enlargement and airway pathologies than WT mice.

\section{Methods \\ Airway CC16 expression in COPD patients and control subjects}

Human studies were approved by institutional review boards and all subjects signed written informed consent forms. Formalin-fixed lung sections were obtained from six patients with severe or very severe COPD as part of the Overholt BlueCross Emphysema Surgery Trial (OBEST) for emphysema [18], six patients with mild-to-moderate COPD, six healthy non-smokers (never smokers) and seven healthy active cigarette smokers (>20 pack-years) without COPD who had undergone lung surgery for benign nodules (see table s1 in the online supplementary material for demographic and clinical data). None of the subjects had lung cancer. Lung sections were double immunostained for CC16 and a marker of airway epithelial cells (pancytokeratin; see the online supplementary material).

\section{Animals}

The Harvard Medical School Institutional Animal Care and Use Committee approved all procedures. C57BL/6 strain $\mathrm{CC} 16^{-/-}$mice [19] and C57BL/6 WT control mice (Jackson Laboratory, Bar Harbor, ME, USA) were studied.

\section{CS exposures}

Adult WT and $\mathrm{CC} 16^{-1-}$ mice (10 weeks old) were exposed to air or mixed mainstream and sidestream CS

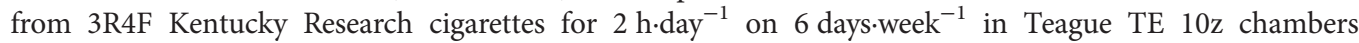
(Teague Enterprises, Woodland, CA, USA) for 1-6 months.

\section{Airway immunostaining for CC16, CYP2F2 and MUC5AC}

Formalin-fixed lung sections from mice were immunostained for CC16, CYP2F2 and MUC5AC (see the online supplementary material).

\section{Airspace enlargement and airway remodelling}

Respiratory mechanics were performed on mice using a mechanical ventilator (FX Flexivent; Scireq Inc, Montreal, QC, Canada). Airspace size was measured on Gill's-stained formalin-fixed and inflated lung sections. Small airway remodelling was measured on lung sections stained with Masson's trichrome stain and immunostained for type-I collagen and fibronectin (see the online supplementary material). 


\section{Lung inflammation}

Leukocyte subsets were counted in BAL samples from mice. Pro-inflammatory mediators and matrix metalloproteinases (MMPs) were measured in lung samples using ELISAs or western blotting (see the online supplementary material).

\section{Alveolar septal cell apoptosis and lung oxidative stress levels}

Alveolar septal cell death was assessed in murine lung sections by terminal deoxynucleotidyl transferase dUTP nick end labelling (TUNEL) staining and immunostaining for active caspase-3. Oxidative stress levels were measured as thiobarbituric acid reactive substances (TBARS) in lung samples (see the online supplementary material).

\section{Cigarette smoke extract-induced apoptosis of murine tracheal epithelial cells}

WT and $\mathrm{CC} 16^{-/-}$murine tracheal epithelial cell (MTEC) monolayers were exposed to $30 \%$ cigarette smoke extract (CSE) at $37^{\circ} \mathrm{C}$ and intracellular active caspase- 3 levels quantified using a fluorogenic substrate specific for active caspase-3 (see the online supplementary material).

\section{Overexpression of mCC16 in murine airways}

Recombinant adenoviral vectors (Vector Biolab, Philadelphia, PA, USA) expressing the cDNA for mCC16 (Ad-CC16) or green fluorescent protein (Ad-GFP) were delivered to the lungs of WT and $\mathrm{CC}^{-/ 6^{-}}$mice $\left(5 \times 10^{7} \mathrm{PFU} \cdot \mathrm{mouse}^{-1}\right)$ at baseline and every 2 weeks thereafter using the oro-pharyngeal aspiration method. One week after the initial viral dose, mice were exposed to air or CS for 1 month, and BAL leukocytes enumerated or lungs removed for analyses.

\section{Nuclear factor- $\kappa B$ activation and secretory phospholipase $A_{2}$ levels in murine lungs}

Lung secretory phospholipase $\mathrm{A}_{2}\left(\mathrm{sPLA}_{2}\right)$ levels were measured using a kit and nuclear factor- $\kappa \mathrm{B}(\mathrm{NF}-\kappa \mathrm{B})$ activation was measured in nuclear extracts of lungs using an electrophoretic mobility shift assay (EMSA) (see the online supplementary material).

\section{Statistical analysis}

Statistical analyses were performed using SigmaStat software (SSPS Inc, San Jose, CA, USA). Data are presented as mean \pm SEM, unless otherwise indicated. A p-value $\leqslant 0.05$ was considered significant.

\section{Results}

Airway CC16 expression is reduced in human smokers and COPD patients, and correlates indirectly with COPD severity

Non-smokers had striking airway CC16 staining whereas staining was less intense in healthy smoker airways (fig. 1). Airway CC16 staining was lowest in COPD airways (fig. 1a) and decreased with increasing COPD severity as assessed by Global Initiative for Chronic Obstructive Lung Disease (GOLD) stage (fig. 1b). Scatter-plot analysis revealed modest variability in staining within the subject groups (fig. s1 in the online supplementary material). The age and sex ratios did not differ between the groups (table s1 in the online supplementary material). All of the COPD patients were former smokers. The GOLD stage III-IV COPD patients had greater pack-year smoking histories than the smokers without COPD. Use of inhaled corticosteroids was higher in GOLD stage III-IV than GOLD stage I-II COPD patients.

\section{CS reduces CC16 expression in murine airways}

Air-exposed WT mice had robust airway CC16 expression (fig. 2a and b). CS exposure caused progressive reductions in airway CC16 expression in mice over time (fig. 2b). Air-exposed $C C 16^{-1-}$ mice had no positive staining for CC16 or CYP2F2, another marker of club cells (fig s2 and s3 in the online supplementary material).

\section{CC16 deficiency increases emphysema development and airway pathologies in CS-exposed mice}

The mean distal airspace size was similar in adult WT and $C C 16^{-/-}$mice that were housed in a room air environment until 10 week of age and then exposed to air for an additional 1 month (fig. $3 \mathrm{a}$ and b). Thus, CC16 does not regulate lung development in mice. When 10-week-old mice were exposed to air for an additional 6 months, $C C 16^{-1-}$ mice had a trend towards increased airspace size compared with WT mice. However, when exposed to CS for 6 months, $\mathrm{CC} 16^{-/}$mice developed $25 \%$ increases in airspace size compared with air-exposed $C C 16^{-/-}$mice, while CS-exposed WT mice developed only $13 \%$ increases in airspace size compared with air-exposed WT mice (fig. 3a and b). Pressure-volume (P-V) flow loops were similar in $\mathrm{CC}_{16^{-/}}$and WT mice exposed to air for 1 month (data not shown) and 6 months (fig. 3c). After 6 months of CS exposure, there was a left shift in the P-V flow loops of CS-exposed $\mathrm{CC}^{-/-}$mice versus CS-exposed WT mice (fig. 3d). Quasi-static lung compliance did not differ in WT and CC16 ${ }^{-/-}$ 
a)
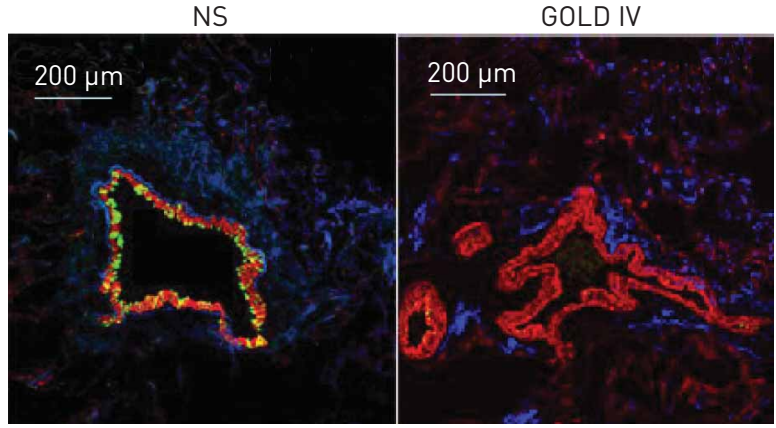

PCK CC16
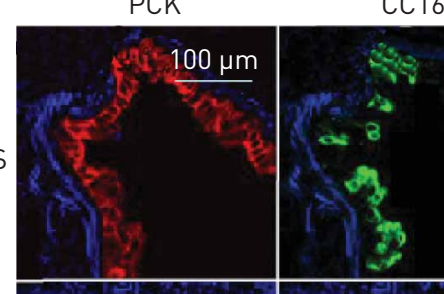

NS

GOLD IV
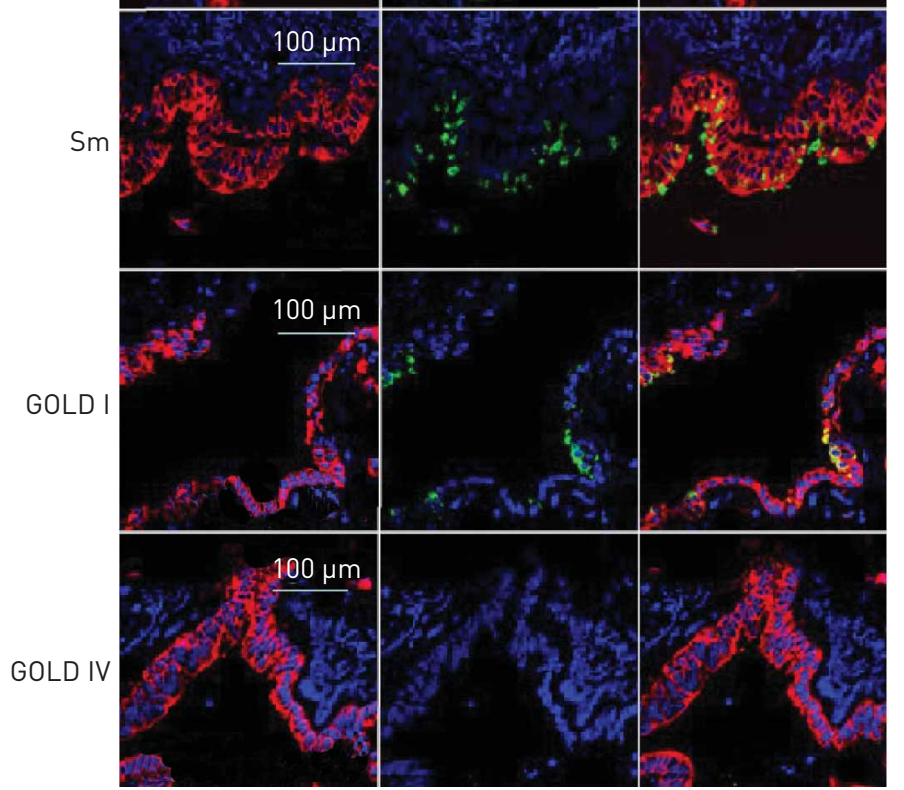

$M s \lg G$

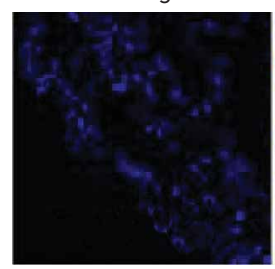

$\mathrm{Rb} \lg G$

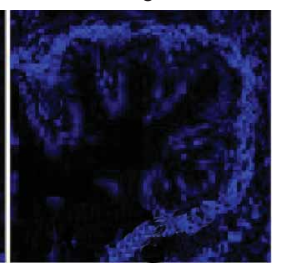

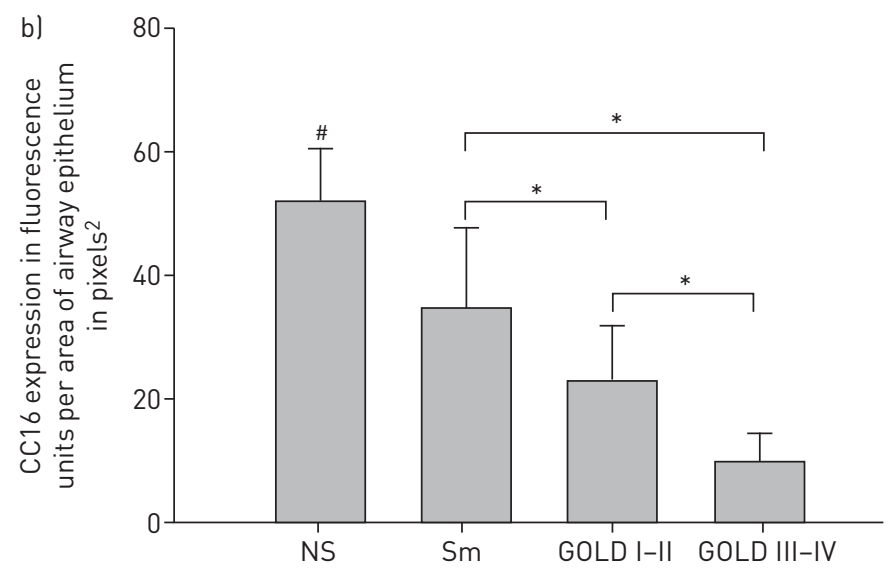

FIGURE 1 CC16 expression is reduced in the large airways of chronic obstructive pulmonary disease (COPD) patients and expression levels decrease with increasing airflow limitation. Double immuno-fluorescence staining for CC16 and a marker of airway epithelial cells (pancytokeratin) was performed on lung sections from six healthy non-smokers (never smokers; NS), six smokers without COPD (Sm), seven Global Initiative for Chronic Obstructive Lung Disease (GOLD) stage I-II COPD patients and six GOLD stage III-IV COPD patients. a) Representative lung sections stained with a red fluorophore and murine IgG to pancytokeratin (PCK; left panels) and with a green fluorophore and rabbit IgG to CC16 (middle panels). DAPI counter-stained lung sections were examined using a confocal microscope. Merged images are shown in the right panels. The top panels of (a) show $\times 100$ magnification merged images of double immunostained stained lung sections from a healthy non-smoker (NS; left) and a very-severe COPD patient (COPD; right). The panels below show representative images (magnification $\times 400-\times 600$ ) of stained lung sections from a healthy non-smoker (NS), a cigarette smoker without COPD (Sm), a GOLD stage II COPD patient, and a GOLD stage IV COPD patient. Lung sections of a non-smoker control stained with non-immune murine IgG (Ms IgG) or non-immune rabbit IgG (Rb IgG) showed no staining. b) Staining for CC16 in airway epithelial cells was quantified in images of the lung sections from the four subject groups (NS, Sm, COPD GOLD I-II, and COPD GOLD III-IV), as described in the Methods section. The size of the airways analysed was similar in all groups (mean \pm SEM internal diameter was $763.85 \pm 174.4,830.9 \pm 110.2$ and $808.8 \pm 64.3 \mu \mathrm{m}$ in the non-smokers, smokers, and COPD patients, respectively). Data are presented as mean \pm SEM; $\mathrm{n}=6-7$ subjects per group. ${ }^{\#}: \mathrm{p}<0.05$ versus all other groups; ${ }^{*}: \mathrm{p}<0.05$. 
a)
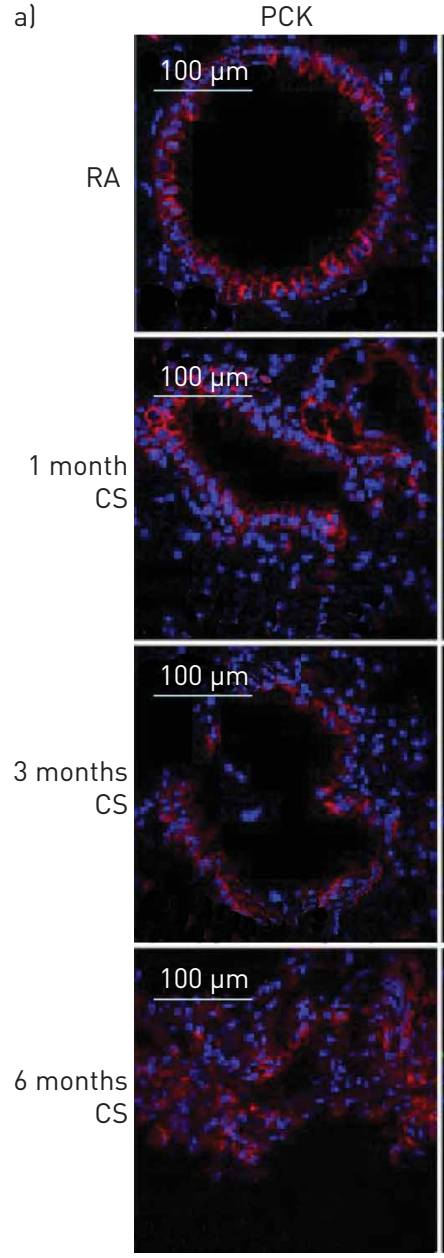

$M s \lg G$

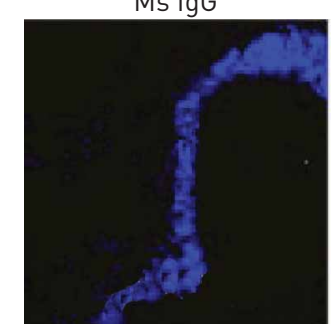

CC16
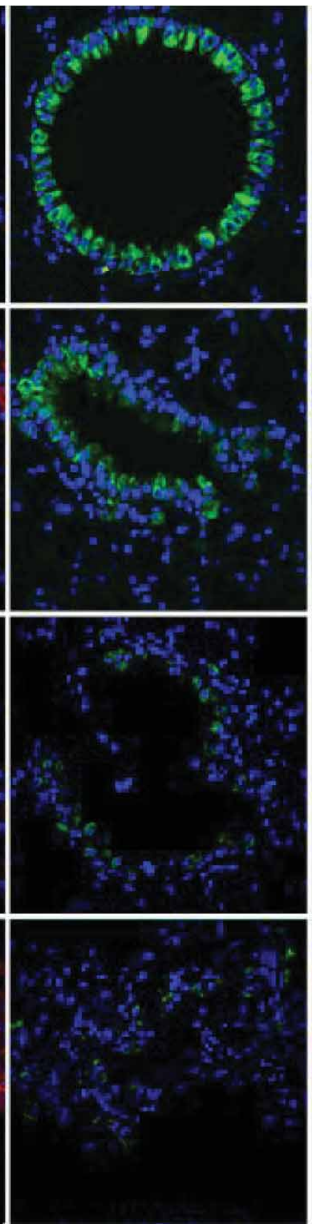

$\mathrm{Rb} \lg G$

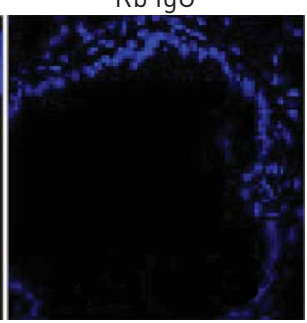

Merge
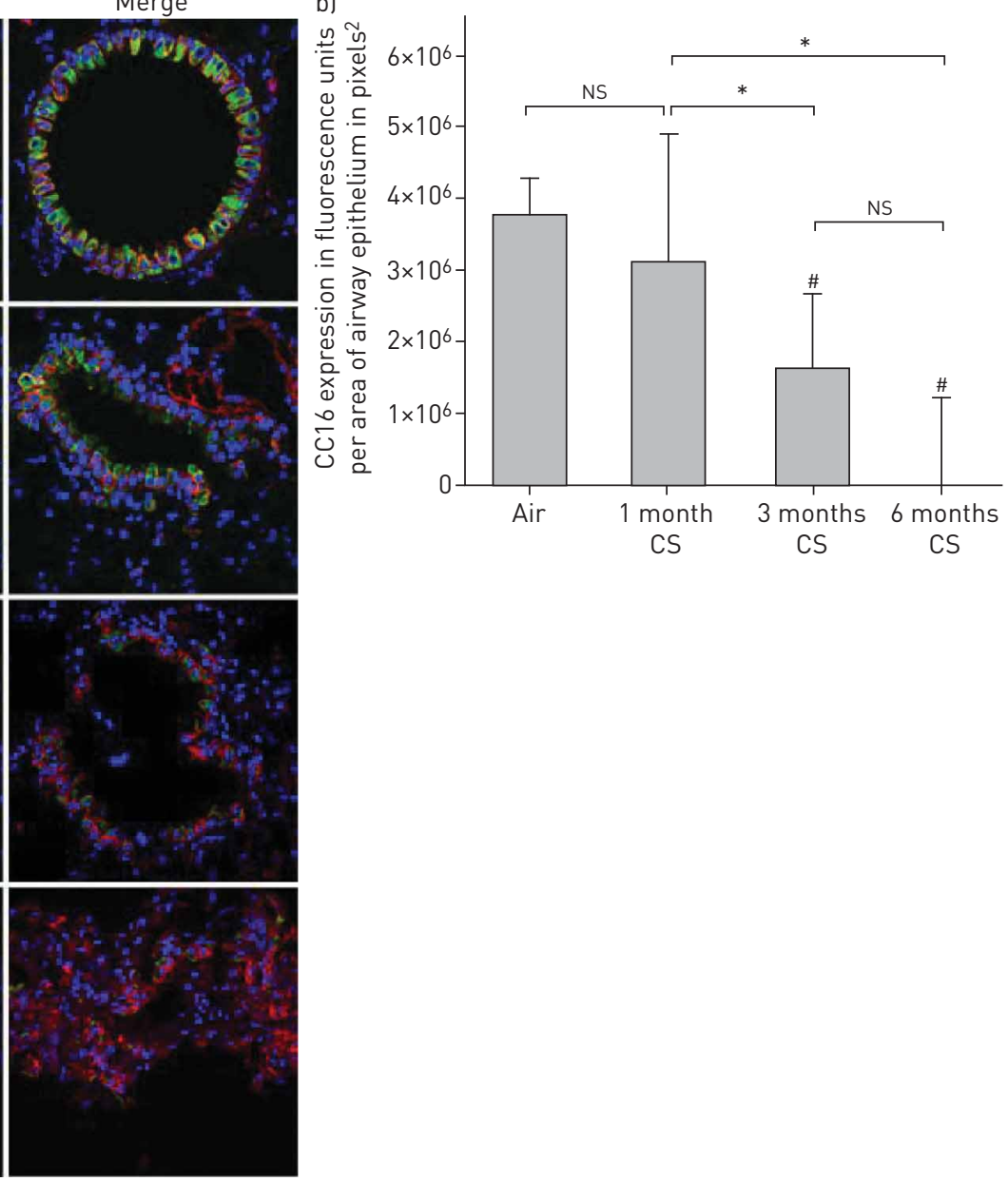

FIGURE 2 Cigarette smoke (CS) exposure reduces the expression of CC16 in murine airways. a) Lung sections from C57BL/6 wildtype mice exposed to room air (RA) or CS for 1, 3, or 6 months were stained with a red fluorophore and a murine IgG to a marker of airway epithelial cells, pancytokeratin (PCK; left panels) and a green fluorophore and a rabbit IgG to CC16 (middle panels). Merged images are shown in the right panels. Lung sections from air-exposed wildtype mice were stained with non-immune murine $\operatorname{IgG}(\mathrm{Ms} \operatorname{IgG})$ or non-immune rabbit $\operatorname{IgG}(\mathrm{Rb} \operatorname{IgG})$. b) Quantitative analysis of airway CC16 normalised per unit of airway area in pixels ${ }^{2}$. Data are presented as mean \pm SEM; $n=6$ air-exposed and $3-4$ CS-exposed mice per group. ${ }^{\#}:$ p $<0.001$ compared with mice exposed to air; ${ }^{*}: \mathrm{p}<0.05$.

mice exposed to air for 1 or 6 months (data not shown) but, after 6 months of CS exposure, it was greater in $C C 16^{-/-}$than WT mice $\left(0.105 \pm 0.00805\right.$ versus $\left.0.0966 \pm 0.00823 \mathrm{~mL} \cdot \mathrm{cmH}_{2} \mathrm{O}^{-1} ; \mathrm{p}=0.036\right)$ consistent with the greater emphysema development in CS-exposed $\mathrm{CC}_{16^{-1-}}$ versus WT mice.

There was a trend $(\mathrm{p}=0.068)$ towards increased deposition of extracellular matrix (ECM) proteins around small airways in adult $\mathrm{CC}_{16^{-1-}}$ mice versus WT mice exposed to air for 1 month (fig. $4 \mathrm{a}$ and b). When mice were exposed to air for 6 months, this small airway remodelling was modestly greater $(\sim 23 \%)$ in $\mathrm{CC} 16^{-1-}$ than WT mice. However, there was a much greater $(\sim 53 \%)$ increase in small airway remodelling in $\mathrm{CC}_{16^{-1-}}$ mice versus WT mice exposed to CS for 6 months (fig. $4 \mathrm{a}$ and b). CS-exposed $\mathrm{CC}^{-16^{-1}}$ mice also had greater staining for type-I collagen (fig. $s 4$ in the online supplementary material) and fibronectin (fig. 4c) around the small airways and greater airway epithelial MUC5AC immunostaining (fig. 4d) than CS-exposed WT mice. 
a)

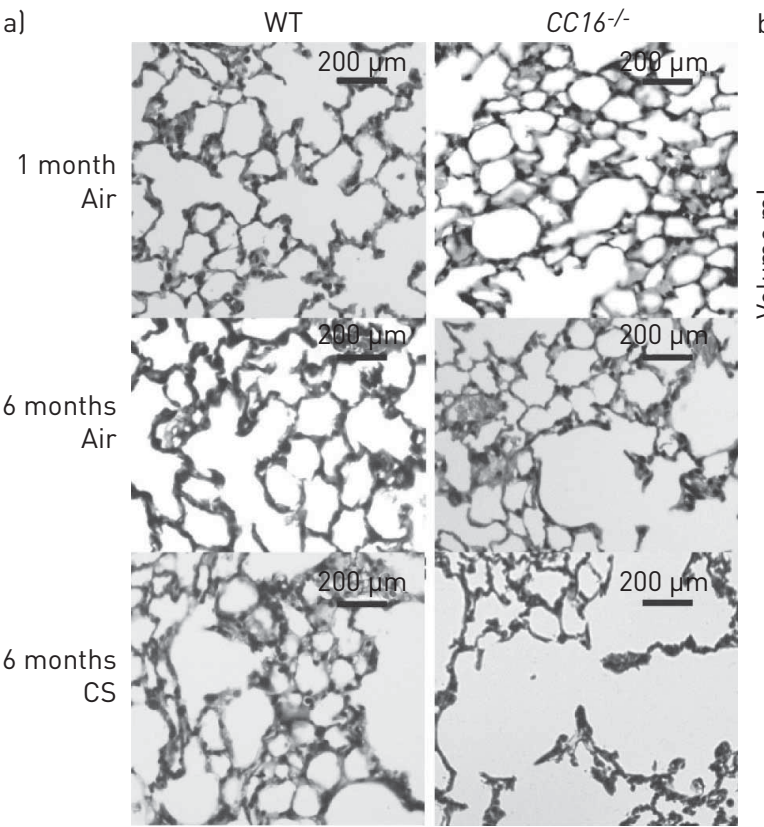

b) 50

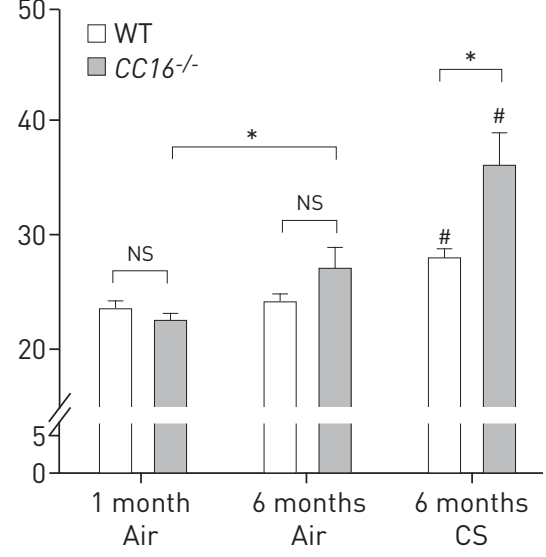

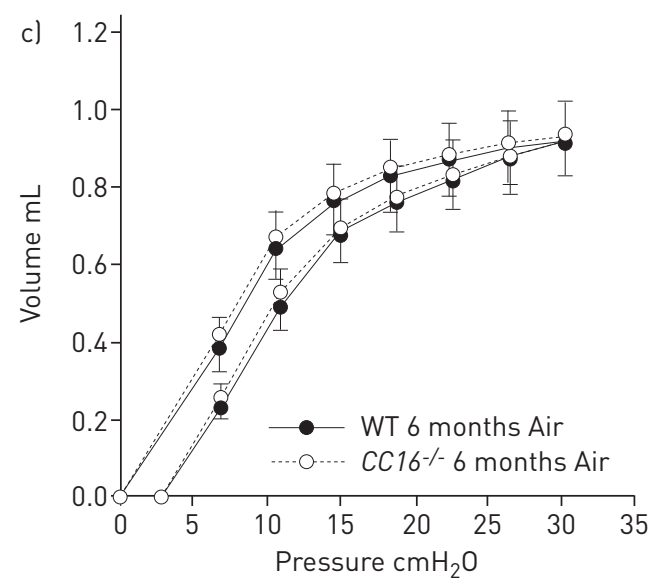

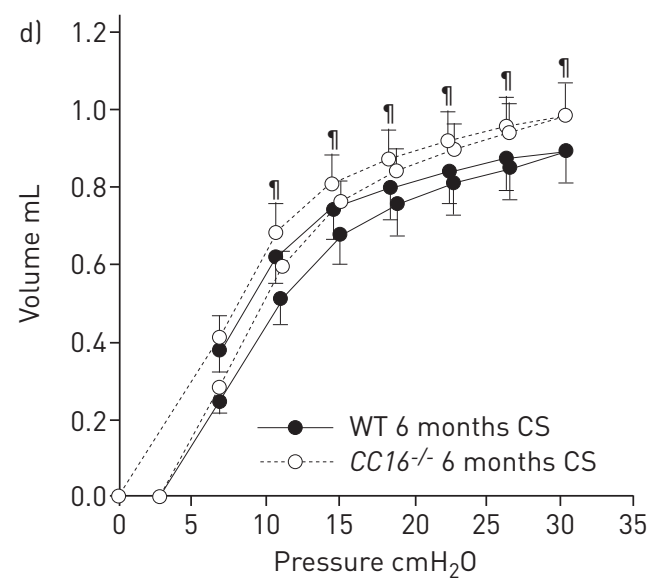

FIGURE $3 \mathrm{CC} 6^{-/-}$mice exposed chronically to cigarette smoke (CS) have greater emphysema and more compliant lungs than CS-exposed wildtype (WT) mice. WT and $\mathrm{CC} 16^{-1-}$ mice were exposed to air for 1 or 6 months, or to CS for 6 months using a Teague device. Airspace enlargement was measured in lung sections as described in the Methods section. a) Representative lung sections from each experimental group studied. b) Alveolar chord lengths (distance between the alveolar walls) in WT versus $C C 16^{-1-}$ mice exposed to air for 1 month (8-9 mice per group) or 6 months (6-15 mice per group), or CS for 6 months (8-9 mice per group). Data are expressed as mean \pm SEM. ${ }^{\#}: \mathrm{p}<0.05$ compared with mice exposed to air for 6 months belonging to the same genotype; ${ }^{*}: \mathrm{p}<0.05$. c, d) A Flexivent device was used to measure pressurevolume flow loops on WT and $C C 16^{-1-}$ mice exposed to air for 6 months (9-10 mice per group) or CS for 6 months (9-10 mice per group). ๆ: $\mathrm{p}<0.05$ versus the corresponding data point on the WT pressure-volume flow loop.

\section{CC16 deficiency increases pulmonary inflammation, MMP-9 levels, and alveolar septal cell apoptosis in CS-exposed mice}

Air-exposed $\mathrm{CC}_{16^{-/}}$mice had modestly greater BAL total leukocyte, macrophage and polymorphonuclear neutrophil (PMN) counts than air-exposed WT mice (fig. 5a-c). CS-exposed $\mathrm{CC}_{16}^{-/-}$mice had higher BAL total leukocyte, macrophage and PMN counts than CS-exposed WT mice at all time-points assessed (fig. 5a-c); however, WT and $C C 16^{-/}$mice did not differ in BAL lymphocyte counts (data not shown). Compared with CS-exposed WT mice, CS-exposed $C C 16^{-1-}$ mice had higher lung levels of CCL5 and active transforming growth factor- $\beta 1$ (TGF- $\beta 1$ ), lower lung levels of interleukin-10, but similar lung levels of other pro-inflammatory mediators (table s2 in the online supplementary material). CS induced greater increases in lung MMP-9 (but not MMP-12) levels in $\mathrm{CC}^{-/ 6^{--}}$mice than WT mice (fig. s5 in the online supplementary material).

CS-exposed $\mathrm{CC} 16^{-/}$mice had increased numbers of apoptotic bronchial epithelial cells (fig. 6a) and apoptotic alveolar septal cells (fig. $6 \mathrm{~b}$ and $\mathrm{c}$ ) as assessed by TUNEL staining and/or staining for active 

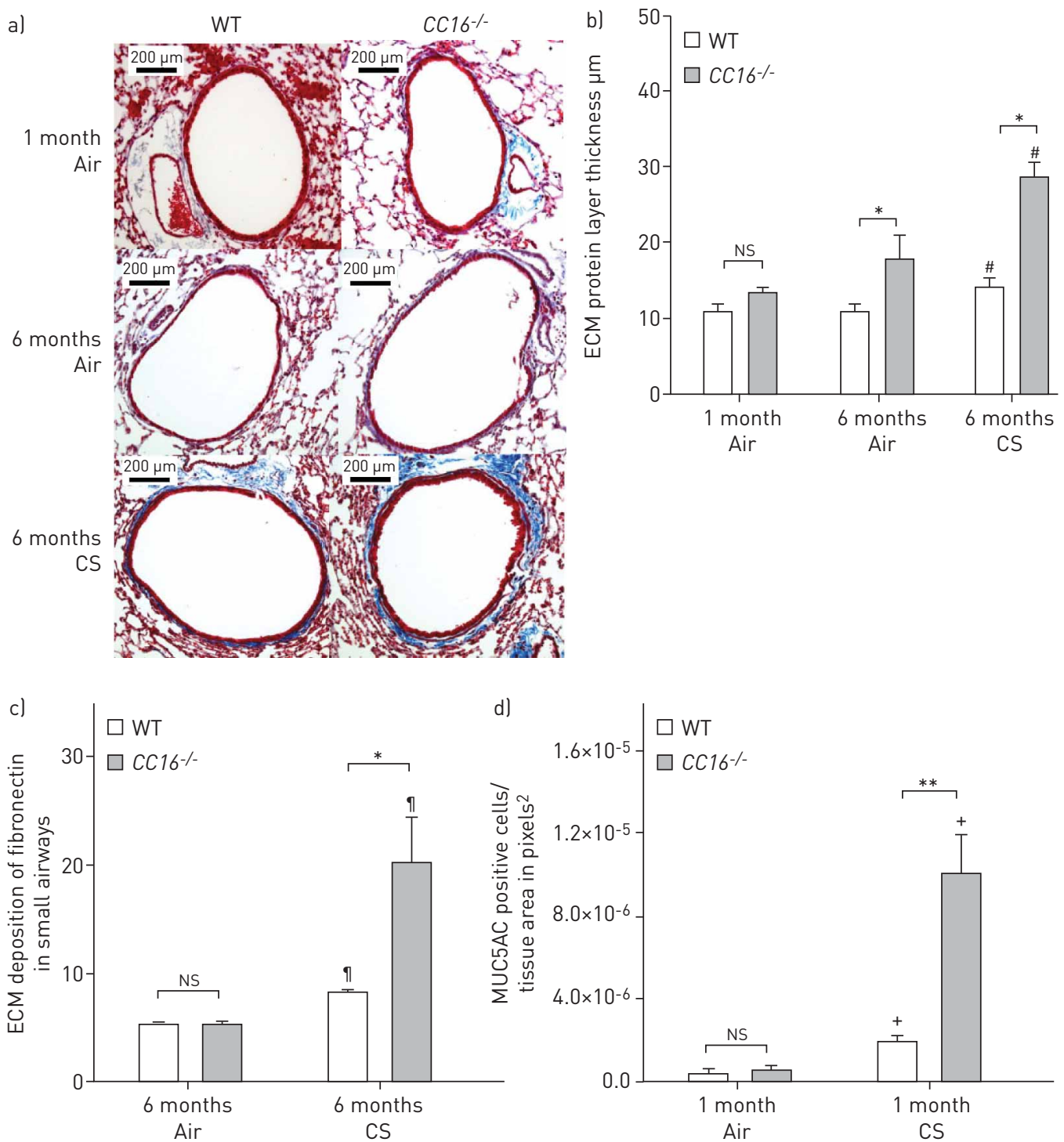

FIGURE 4 Small airway remodelling is greater in $C C 16^{-/-}$mice compared with wildtype (WT) mice exposed to cigarette smoke (CS). Starting at 10 weeks of age, WT and $C C 16^{-1-}$ mice were exposed to air or CS for 1 or 6 months. Deposition of extracellular matrix (ECM) proteins around small airways (mean diameter 300-699 $\mu \mathrm{m}$ ) was quantified in Masson's trichrome-stained lung sections. a) Representative stained lung sections from each experimental group. ECM proteins deposited around the small airways are stained in blue. b) The thickness of the ECM protein layer deposited around small airways (airways having an internal diameter 300-699 $\mu \mathrm{m}$ ) was quantified as described in the Methods section. Data are presented as mean \pm SEM; $n=6-7$ mice exposed to air for 1 month, $n=5-9$ mice exposed to air for 6 months and $n=7-8$ mice exposed to CS for 6 months. ${ }^{\#}$ : $p<0.05$ compared with mice exposed to air for 6 months belonging to the same genotype; ${ }^{*}: \mathrm{p}<0.05$. c) Lung sections from WT and $C C 16^{-1-}$ mice exposed to air (3-4 mice per group) or CS (4 mice per group) for 6 months were immuno-stained for fibronectin as described in the Methods section. The thickness of the layer of fibronectin deposited around small airways (internal diameter 300-699 $\mu \mathrm{m}$ ) was quantified. ๆ: $\mathrm{p}<0.05$ compared with mice exposed to air belonging to the same genotype; ${ }^{*}: \mathrm{p}<0.05$. d) Lung sections from WT and $C C 16^{-1-}$ mice exposed to air (3-5 mice per group) or CS (3-5 mice per group) for 1 month were immunostained for MUC5AC as described in the Methods section. The number of all bronchial epithelial cells that stained positively for MUC5AC was quantified. Data are presented as mean \pm SEM. ${ }^{+}: \mathrm{p}<0.05$ compared with air-exposed mice belonging to the same genotype; ${ }^{* *}: \mathrm{p}<0.01$.

caspase-3. However, CSE induced similar rates of apoptosis in $C C 16^{-/}$and WT MTEC cultures in vitro (fig. s6 in the online supplementary material). Lung oxidative stress levels were similar in CS-exposed $\mathrm{CC}_{16^{-/}}$and WT mice measured as lung levels of TBARS (a readout of lipid peroxidation; not shown).

\section{CC16 deficiency increases activation of NF-кB but not SPLA 2 levels in CS-exposed lungs}

CC16 inhibits two pro-inflammatory pathways in other model systems: NF- $\kappa B$ activation [20] and sPLA 2 activity by binding co-factors for this enzyme [21]. When we measured these pathways, air-exposed 

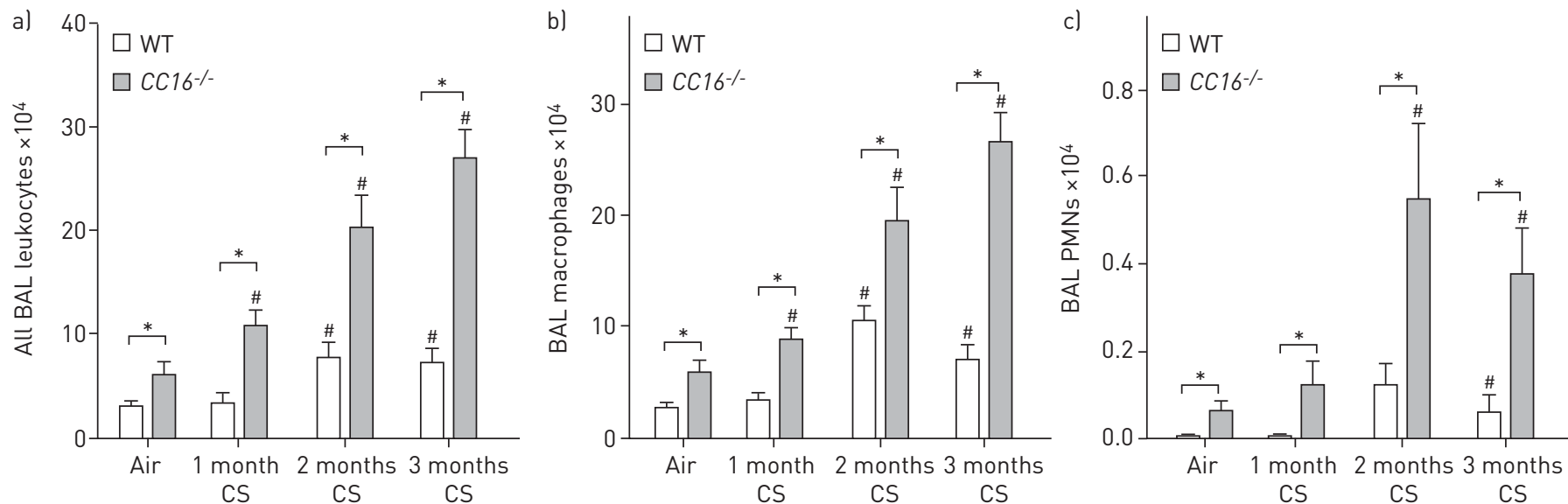

FIGURE 5 Lung inflammation is increased in cigarette smoke (CS)-exposed CC16 ${ }^{-1-}$ mice. Wildtype (WT) and CC16 ${ }^{-1-}$ mice were exposed to air or CS for 1-3 months. Absolute numbers of a) all leukocytes, b) macrophages, and c) polymorphonuclear neutrophils (PMNs) were counted in bronchoalveolar lavage (BAL) samples. Data are presented as mean \pm SEM; $n=7$ air-exposed mice, $n=7-10$ mice exposed to CS for 1 month; $n=8$ mice exposed to CS for 2 months, and $\mathrm{n}=5-14$ mice exposed to CS for 3 months. ${ }^{*}: \mathrm{p}<0.05$ compared with air-exposed mice belonging to the same genotype; ${ }^{*}: \mathrm{p}<0.05$.

$C C 16^{-/-}$mice had modestly increased NF- $\mathrm{BB}$ activation in their lungs as assessed by EMSA. However, $\mathrm{CS}$-exposed $\mathrm{CC}^{-/ 6^{-}}$mice had greater NF- $\mathrm{KB}$ activation in their lungs than CS-exposed WT mice (fig. $7 \mathrm{a}$ and b). Although air-exposed $\mathrm{CC}^{-/-}$mice had higher lung levels of active sPLA 2 than air-exposed WT mice, sPLA 2 levels were similar in lung homogenates (fig. $7 \mathrm{c}$ ) and BALF (fig. $s 7$ in the online supplementary material) from CS-exposed WT and $\mathrm{CC}^{-/ 6^{-/}}$mice.

\section{Adenoviral-mediated CC16 overexpression in murine airways reduces pulmonary pathologies induced by acute CS exposure}

Delivering Ad-CC16 to the airways of $\mathrm{CC} 16^{-/-}$mice induced airway immunostaining for CC16 (fig. s8 in the online supplementary material). Delivering Ad-CC16 to both $\mathrm{CC}_{1}{ }^{-/}$and WT lungs attenuated CS-induced increases in BAL macrophage (but not PMN) counts in both genotypes compared with macrophage counts in Ad-GFP-treated mice (fig. 8a or not shown). Ad-CC16-treated $\mathrm{CC}^{-/-}$and WT mice had lower CS-induced airway MUC5AC immunostaining, alveolar septal cell apoptosis and lung NF- $\kappa \mathrm{B}$ activation (fig. $8 \mathrm{~b}-\mathrm{d}$ ), but similar lung levels of $\mathrm{SPLA}_{2}$ activity (data not shown) than Ad-GFP-treated mice belonging to the same genotype.
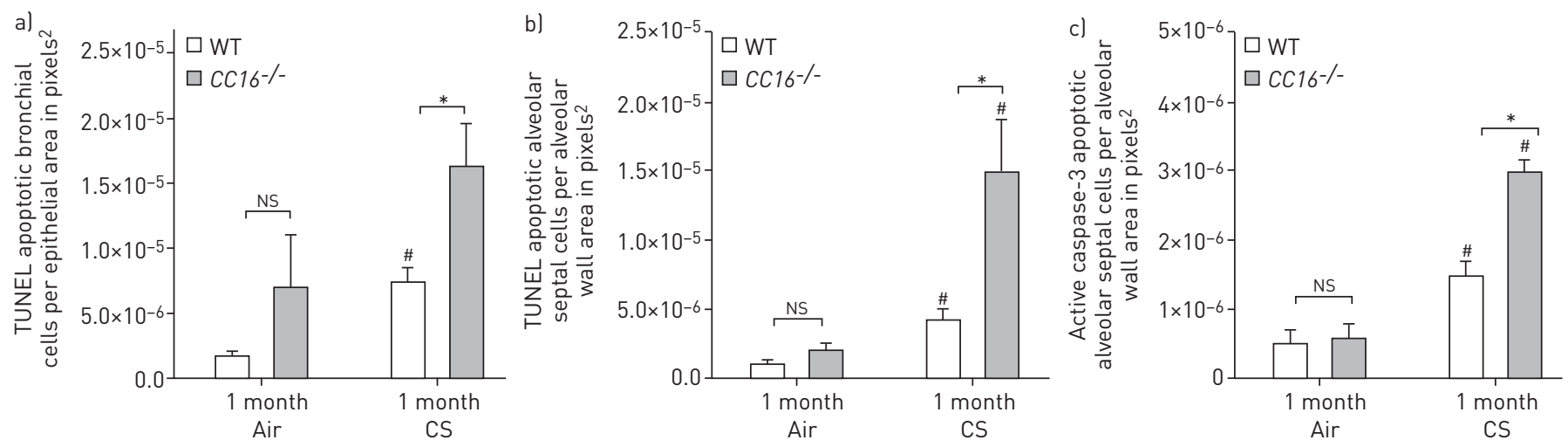

FIGURE 6 Apoptosis rates are increased in bronchial epithelial and alveolar septal cells in $C C 16^{-1-}$ mice exposed to cigarette smoke (CS). Terminal deoxynucleotidyl transferase dUTP nick-end labelling (TUNEL) staining and immunostaining for active (cleaved) caspase-3 was performed on formalin-fixed lung sections from wildtype (WT) versus $C C 16^{-1}$ mice exposed to air or CS for 1 month. a) TUNEL-positive cells were quantified in large and medium-sized airways from three air-exposed WT or $C C 16^{-/-}$mice and four CS-exposed WT or CC16 ${ }^{-1-}$ mice. b) TUNEL-positive alveolar septal cells were counted and counts were normalised to unit area of alveolar wall in four air-exposed WT or CC16 ${ }^{-1-}$ mice and four CS-exposed WT or CC16 ${ }^{-1-}$ mice. c) Alveolar septal cells that stained positively for active (cleaved) caspase- 3 were counted and counts were normalised per unit area of alveolar wall in 4 mice per experimental condition. Data are mean \pm SEM. ${ }^{\#}: \mathrm{p}<0.05$ compared with air-exposed mice belonging to the same genotype; ${ }^{*}: \mathrm{p}<0.05$. 
a)

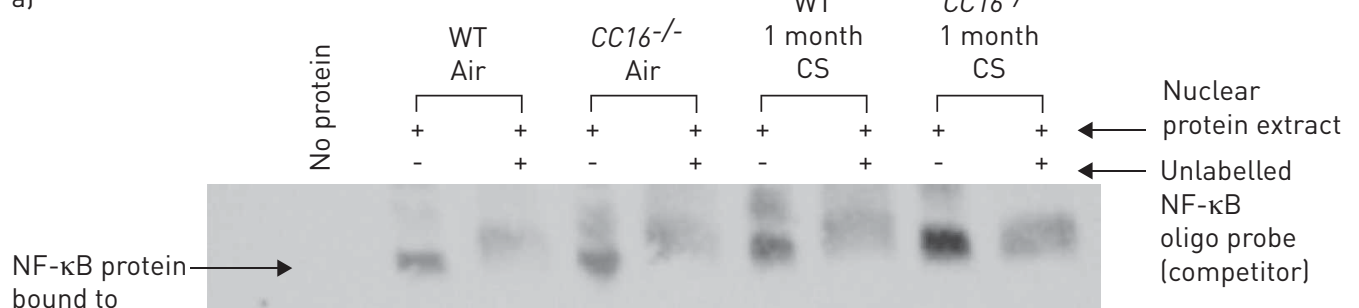

biotin-labelled

oligo probe
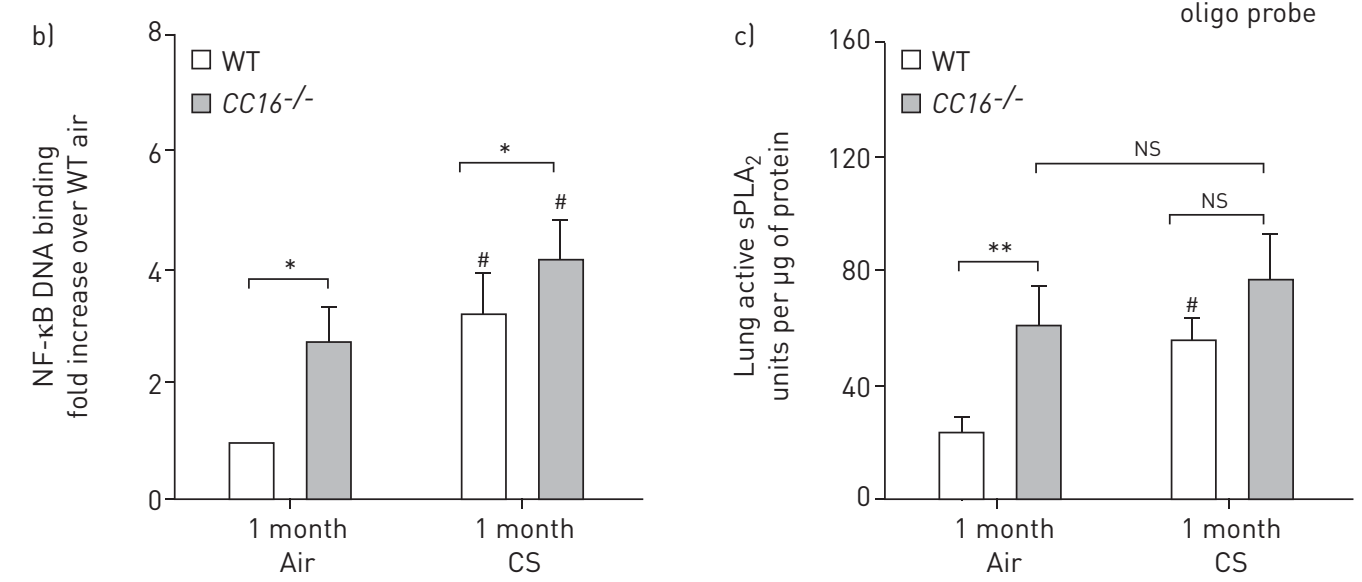

FIGURE 7 Nuclear factor (NF)-KB activation is increased in the lungs of cigarette smoke (CS)-exposed $\mathrm{CC}^{-16^{-1}}$ mice. Wildtype (WT) and $C C 16^{-1-}$ mice were exposed to air or CS for 1 month. Nuclear extracts were prepared from the lungs of five WT or $C C 16^{-1-}$ mice exposed to air and six WT or $C C 16^{-1-}$ mice exposed to CS and equal amounts of protein $\left(2 \mu \mathrm{g} \mathrm{sample}{ }^{-1}\right)$ were subjected to electrophoretic mobility shifts assays (EMSAs) using a labelled oligonucleotide probe containing the NF- $\mathrm{KB}$ consensus sequence. Assays were performed in the presence and absence of excess unlabelled probe to identify NF- $\mathrm{KB}$ protein bound specifically to the probe. a) Representative image of an EMSA analysis of nuclear extracts from all experimental groups. Note the marked reduction in signal in the band indicated by the arrow when excess unlabelled probe is added, indicating specific binding of NF- $\kappa B$ present in nuclear extracts to the labelled oligonucleotide probe. b) The intensities of the bands corresponding to NF- $\mathrm{\kappa B}$ oligonucleotide complexes were quantified using densitometry, and band intensities for all groups were normalised to signals in the air-exposed WT lungs. Data are presented as mean \pm SEM from six independent experiments. ${ }^{\#}: \mathrm{p}<0.01$ compared with air-exposed mice belonging to the same genotype; ${ }^{*}: \mathrm{p}<0.05$. c) Lung levels of active secretory phospholipase $\mathrm{A}_{2}\left(\mathrm{sPLA}_{2}\right)$ were measured in homogenates of lungs from mice exposed to air or CS for 1 month using a commercial kit, and levels were normalised to lung total protein levels. Data are presented as mean \pm SEM; $n=10$ air-exposed mice and $n=11-12$ CS-exposed mice. ${ }^{\#}: \mathrm{p}<0.05$ compared with air-exposed mice belonging to the same genotype; ${ }^{* *}: \mathrm{p}<0.01$.

\section{Discussion}

We report several novel findings. First, airway CC16 expression was lower in COPD patients than smokers and non-smokers, and indirectly correlated with airflow obstruction. Second, CS exposure progressively reduced airway CC16 expression in WT mice. Third, CS-exposed $C C 16^{-1-}$ mice developed greater pulmonary inflammation, alveolar septal cell apoptosis, airway mucus metaplasia, emphysema and small airway remodelling, associated with greater NF- $\mathrm{\kappa B}$ activation in their lungs than WT mice. Pulmonary pathologies induced by acute CS exposure were attenuated by adenoviral-mediated over-expression of CC16 in murine airways. Thus, CC16 has important roles in protecting murine lungs from the development and 

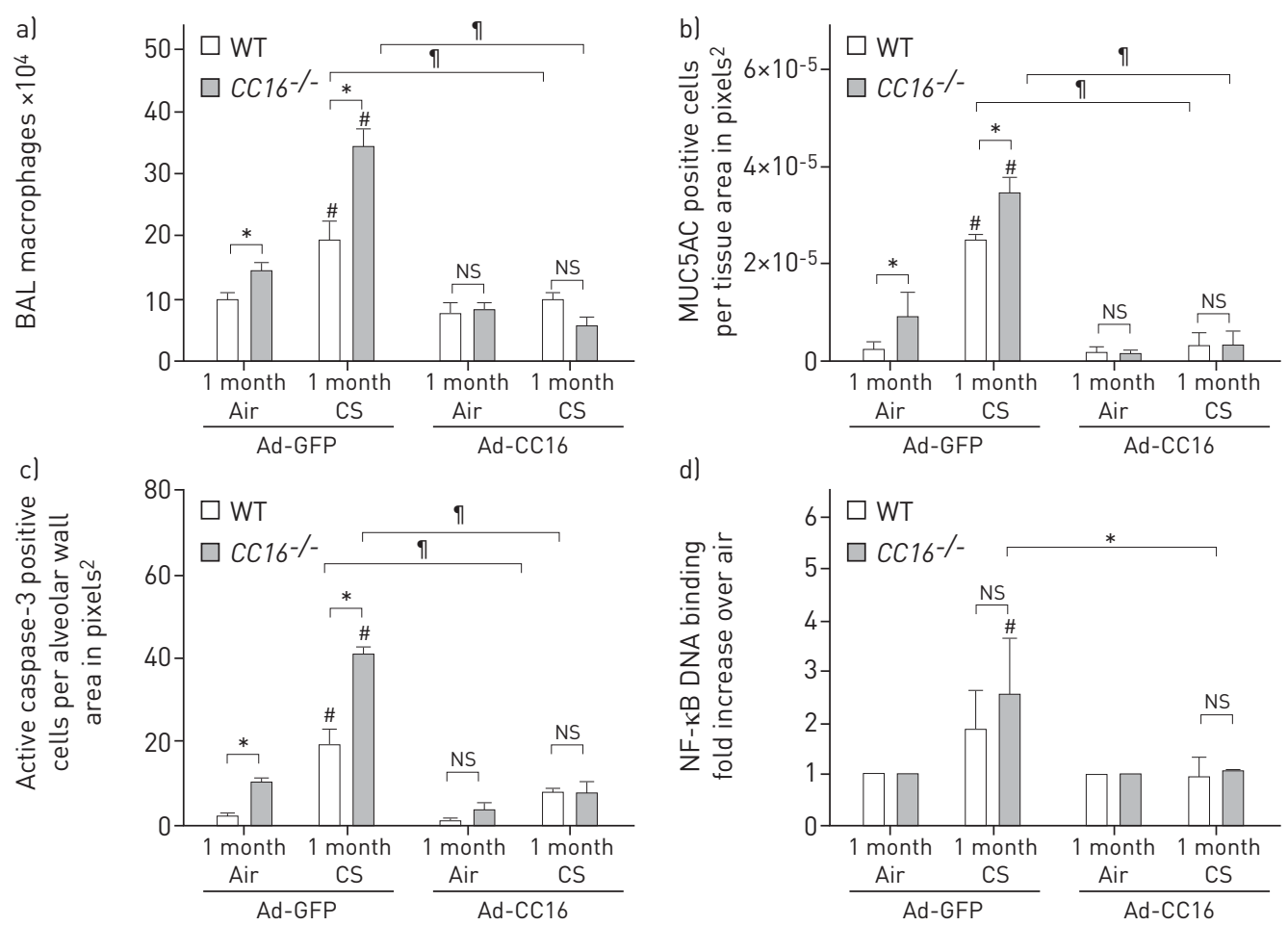

FIGURE 8 Adenoviral-mediated CC16 overexpression in murine airways decreases pulmonary inflammation, alveolar septal cell apoptosis, and airway mucus metaplasia. Ad-CC16 or Ad-GFP were delivered to wildtype (WT) and CC16 ${ }^{-1-}$ mice and 1 week later, the mice were exposed to air or cigarette smoke (CS) for 1 month. Adenoviral vector delivery was repeated every 2 weeks for the duration of the CS exposures. a) Macrophage numbers were counted in bronchoalveolar lavage (BAL) samples. Data are presented as mean \pm SEM; $n=7-10$ mice treated with Ad-GFP and exposed to air, $n=9$ mice treated with Ad-GFP exposed to CS, n=8-10 treated with Ad-CC16 and exposed to air and n=7-9 mice treated with Ad-CC16 and exposed to CS. b) The number of alveolar septal cells staining positively for active (cleaved) caspase- 3 was counted and counts were normalised per unit area of alveolar wall. Data are presented as mean \pm SEM; $\mathrm{n}=4$ mice per group. c) Lung sections from Ad-CC16- or Ad-GFP-treated WT or CC16 ${ }^{-/-}$mice exposed to air or CS for 1 month (4 mice per group) were immunostained for MUC5AC. The number of bronchial epithelial cells that stained positively for MUC5AC was quantified and normalised per unit area of airway epithelium. Data are presented as mean \pm SEM. ${ }^{\#}: \mathrm{p}<0.05$ compared with air-exposed mice belonging to the same genotype and treated with the same adenoviral vector; ${ }^{*}: \mathrm{p}<0.05$ and ${ }^{\text {I: }} \mathrm{p}<0.05$ compared with CS-exposed mice belonging to the same genotype and treated with Ad-CC16 versus Ad-GFP.

progression of CS-induced COPD-like pathologies in mice (at least in part) by reducing activation of $\mathrm{NF}-\mathrm{kB}$ in the lung which has been implicated in the pathogenesis of COPD [22].

\section{Human studies}

Only one prior study has reported decreased airway CC16 expression in severe COPD patients versus cigarette smokers [23]. We now link airway CC16 deficiency to smoking in human subjects and the severity of airflow limitation in COPD. Reduced airway CC16 expression in COPD lungs may be persistent as our very severe COPD patients had stopped smoking well before the tissue was obtained. However, a prior study reported that serum CC16 levels recover somewhat when smokers without COPD quit smoking [16]. The differences in these findings could be due to differences in study populations, the samples studied or the length of time since smoking cessation.

\section{Murine studies}

CS exposure progressively reduced murine airway CC16 expression which could be due to reduced synthesis of CC16 by club cells or loss of airway club cells [24]. Club cells have the highest levels of cytochrome P450 in the lung and are the main site of lung detoxification of xenobiotics [25]. Murine club cells are sensitive to injury following inhalation of naphthalene (a component of CS [26]) or CS itself [24]. Polymorphisms in the CC16 locus were weakly linked to COPD in the ECLIPSE cohort and associated with low plasma CC16 levels, but these findings were not replicated in other smaller COPD cohorts having different inclusion criteria [27]. Additionally, the CC16 locus is hyper-methylated in COPD bronchial epithelia suggesting that epigenetic factors influence CC16 expression [28]. Although CS reduced 
airway CC16 expression in WT mice, some CC16 was detected after 3 months of CS exposure that likely was sufficient to protect the WT lung from developing the more severe lung inflammatory response and airway and airspace disease observed in CS-exposed $C C 16^{-/-}$mice.

CC16 protects the murine lung from CS-induced pulmonary inflammation, emphysema development, small airway remodelling and airway mucus metaplasia. Likely, the protective effect of CC16 in the CS-exposed murine lung is due to CC16 reducing lung macrophage and PMN counts and protecting alveolar septal cells from CS-induced apoptosis. CC16 secreted by club cells into the epithelial lining fluid likely has paracrine crytoprotective effects on other lung epithelial cells as club cell-free WT and CC16 ${ }^{-/-}$ lung epithelial cells had similar rates of CSE-induced apoptosis in vitro.

$\mathrm{NF}-\kappa \mathrm{B}$ activation was increased in CS-exposed $\mathrm{CC}_{16^{-1}}$ versus WT lungs (fig. 7) and was reduced in both CS-exposed WT and $\mathrm{CC}_{16}{ }^{-/-}$lungs by over-expressing CC16 in their airways, indicating that CC16 mediates its activities (at least in part) in the CS-exposed lung by reducing NF- $\kappa \mathrm{B}$ activation which promotes inflammation in COPD lungs [22]. Ad-GFP-treated WT and $\mathrm{CC}^{-1} 6^{--}$mice did not differ in the extent to which CS increased NF- $\kappa \mathrm{B}$ activation in their lungs which may be due to virus-induced NF- $\kappa \mathrm{B}$ activation, but virus-mediated over-expression of CC16 attenuated NF- $\mathrm{KB}$ activation in the lungs of CS-exposed WT and $\mathrm{CC}_{16^{-/}}$mice. CC16 signals through the N-formyl-Met-Leu-Phe receptor on granulocytes [29], the lipocalin-1 receptor on lung epithelial carcinoma cells [30] and cubilin in the kidney [31], and reduces macrophage toll-like receptor 4 levels [32]. CC16 also inhibits $\mathrm{SPLA}_{2}$ activity in other models by binding its co-factors [21] and elevated sPLA 2 BALF levels correlate with a pro-inflammatory phenotype in COPD patients [33]. While $\mathrm{CC} 16^{-/-}$mice had higher baseline lung $\mathrm{SPLA}_{2}$ activity levels, CS-exposed WT and $\mathrm{CC}_{16^{-/}}$mice had similar lung levels of sPLA $\mathrm{P}_{2}$ The increased baseline $\mathrm{SPLA}_{2}$ levels may have contributed to the increased BAL leukocyte counts in air-exposed $\mathrm{CC}_{16}{ }^{-1-}$ mice. However, CC16 could mediate some of its anti-inflammatory effects in the CS-exposed lung by inhibiting sPLA 2 activity as measuring this mediator in whole lung or BALF samples may dilute $\mathrm{PLA}_{2}$ signals generated by subpopulations of pulmonary cells.

CC16 may reduce airway ECM deposition in CS-exposed lungs by reducing lung levels of active TGF-1 $\beta$ as levels of this mediator were higher in CS-exposed $\mathrm{CC}^{-/ 6^{-1}}$ versus WT lungs. CC16 could also reduce small airway remodelling and airway MUC5AC expression by restraining pulmonary inflammation as leukocyte products contribute to airway remodelling and mucin gene expression in rodents [34-36].

Our findings differ from those recently reported by PARK et al. [8] who reported that pulmonary inflammation, emphysema, and airway remodelling are similar in CS-exposed WT and $C C 16^{-1}$ mice. Different $\mathrm{CC} 16^{-1-}$ strains vary in the severity of renal phenotypes detected [37-39] due to differences in their genetic backgrounds and/or the targeting constructs used to generate the mice. However, both studies evaluated the same $\mathrm{CC} 6^{-1}$ murine stain [19] (personal communication, Don Sin; University of British Columbia, Vancouver, British Columbia, Canada). Likely, the differences in the results of the two studies reflect differences in the methods used. For example, we exposed mice to whole-body mixed mainstream and side-stream CS for $2 \mathrm{~h} \cdot$ day $^{-1}$ for 6 days.week ${ }^{-1}$, whereas PARK et al. [8] exposed the mice to mainstream CS from 3 cigarettes 5 days.week ${ }^{-1}$ using a nose-only technique. However, we also over-expressed CC16 in the airways of mice using adenoviral vectors which reduced CS-induced acute pulmonary changes consistent with our hypothesis that CC16 has anti-inflammatory activities in the CS-exposed lung.

We observed small increase in pulmonary inflammation and small airway remodelling in air-exposed $C C 16^{-1-}$ mice versus WT mice. Small increases in lung leukocyte counts were detected after just 1 month of air exposure. Thus, deficiency of CC16 in the absence of CS is sufficient to cause mild pulmonary inflammation which may contribute to the modestly greater small airway remodelling in air-exposed $\mathrm{CC}_{16}{ }^{-/-}$versus WT mice. Thus, CC16 has anti-inflammatory activities even in the unchallenged lung.

Limitations of our study include our relatively small sample sizes. Nevertheless, we achieved statistically significant differences between our groups and scatter-plot analysis revealed modest within-group variability in airway CC16 staining in our human subjects. The GOLD stage III-IV COPD patients had greater pack-year smoking histories than the smoker controls. All of the smokers but none of the COPD patients were current smokers which could have influenced airway CC16 staining. The use of inhaled corticosteroids by some of the COPD patients may have increased their airway CC16 expression as CC16 is steroid-responsive gene [40].

\section{Conclusions}

CS exposure reduces airway CC16 expression leading to increased pulmonary inflammation, alveolar septal cell apoptosis, mucus metaplasia, as well as emphysema development and small airway remodelling which both contribute to airflow obstruction in COPD patients. Pulmonary pathologies induced by acute CS exposure are reversed by adenoviral-mediated over-expression of CC16 in both WT and CC16 ${ }^{-/-}$airways. 
Thus, CC16 protects lungs from CS-induced injury. Future studies will determine whether CC16 can be used as a novel therapy for COPD.

\section{References}

1 Murray CJ, Lopez AD. Measuring the global burden of disease. N Engl J Med 2013; 369: 448-457.

2 Owen CA. Roles for proteinases in the pathogenesis of chronic obstructive pulmonary disease. Int $J$ Chron Obstruct Pulmon Dis 2008; 3: 253-268.

3 Swanney MP, Ruppel G, Enright PL, et al. Using the lower limit of normal for the FEV $1 / F V C$ ratio reduces the misclassification of airway obstruction. Thorax 2008; 63: 1046-1051.

4 Vestbo J, Edwards LD, Scanlon PD, et al. Changes in forced expiratory volume in 1 second over time in COPD. N Engl J Med 2011; 365: 1184-1192.

5 Casanova C, de Torres JP, Aguirre-Jaime A, et al. The progression of chronic obstructive pulmonary disease is heterogeneous: the experience of the BODE cohort. Am J Respir Crit Care Med 2011; 184: 1015-1021.

6 Nishimura M, Makita H, Nagai K, et al. Annual change in pulmonary function and clinical phenotype in chronic obstructive pulmonary disease. Am J Respir Crit Care Med 2012; 185: 44-52.

7 Lomas DA, Silverman EK, Edwards LD, et al. Evaluation of Serum CC-16 as a biomarker for COPD in the ECLIPSE cohort. Thorax 2008; 63: 1058-1063.

8 Park HY, Churg A, Wright JL, et al. Club cell protein 16 and disease progression in chronic obstructive pulmonary disease. Am J Respir Crit Care Med 2013; 188: 1413-1419.

9 Stripp BR, Reynolds SD, Boe IM, et al. Clara cell secretory protein deficiency alters Clara cell secretory apparatus and the protein composition of airway lining fluid. Am J Respir Cell Mol Biol 2002; 27: 170-178.

10 Dodge DE, Rucker RB, Pinkerton KE, et al. Dose-dependent tolerance to ozone. III. Elevation of intracellular Clara cell 10-KDa protein in Central Acini of rats exposed for 20 months. Toxicol Appl Pharmacol 1994; 127: 109-123.

11 Chen LC, Zhang Z, Myers AC, et al. Cutting edge: altered pulmonary eosinophilic inflammation in mice deficient for Clara cell secretory 10-KDa protein. J Immunol 2001; 167: 3025-3028.

12 Wang SZ, Rosenberger CL, Bao YX, et al. Clara cell secretory protein modulates lung inflammatory and immune responses to respiratory syncytial virus infection. J Immunol 2003; 171: 1051-1060.

13 Bernard AM, Roels HA, Buchet JP, et al. Serum Clara cell protein: an indicator of bronchial cell dysfunction caused by tobacco smoking. Environ Res 1994; 66: 96-104.

14 Laing IA, Hermans C, Bernard A, et al. Association between plasma CC16 levels, the A38G polymorphism, and asthma. Am J Respir Crit Care Med 2000; 161: 124-127.

15 Mattsson J, Remberger M, Andersson O, et al. Decreased serum levels of Clara cell secretory protein (CC16) are associated with bronchiolitis obliterans and may permit early diagnosis in patients after allogeneic stem-cell transplantation. Transplantation 2005; 79: 1411-1416.

16 Chen J, Lam S, Pilon A, McWilliams A, et al. The association between the anti-inflammatory protein CC10 and smoking status among participants in a chemoprevention trial. Cancer Epidemiol Biomarkers Prev 2007; 16: 577-583.

17 Chen J, Lam S, Pilon A, et al. Higher levels of the anti-inflammatory protein CC10 are associated with improvement in bronchial dysplasia and sputum cytometric assessment in individuals at high risk for lung cancer. Clin Cancer Res 2008; 14: 1590-1597.

18 Berger RL, Celli BR, Meneghetti AL, et al. Limitations of randomized clinical trials for evaluating emerging operations: the case of lung volume reduction surgery. Ann Thorac Surg 2001; 72: 649-657.

19 Stripp BR, Lund J, Mango GW, et al. Clara cell secretory protein: a determinant of PCB bioaccumulation in mammals. Am J Physiol 1996; 271: L656-L664.

20 Long XB, Hu S, Wang N, et al. Clara cell 10-KDa protein gene transfection inhibits NF-KappaB activity in airway epithelial cells. PLoS ONE 2012; 7: e35960.

21 Andersson O, Nordlund-Moller L, Barnes HJ, et al. Heterologous expression of human uteroglobin/ polychlorinated biphenyl-binding protein. Determination of ligand binding parameters and mechanism of phospholipase A2 inhibition in vitro. J Biol Chem 1994; 269: 19081-19087.

22 Gagliardo R, Chanez P, Profita M, et al. IkappaB kinase-driven nuclear factor-KappaB activation in patients with asthma and chronic obstructive pulmonary disease. J Allergy Clin Immunol 2011; 128: 635-645.

23 Pilette C, Godding V, Kiss R, et al. Reduced epithelial expression of secretory component in small airways correlates with airflow obstruction in chronic obstructive pulmonary disease. Am J Respir Crit Care Med 2001; 163: $185-194$.

24 Adair-Kirk TL, Atkinson JJ, Griffin GL, et al. Distal airways in mice exposed to cigarette smoke: Nrf2-regulated genes are increased in Clara cells. Am J Respir Cell Mol Biol 2008; 39: 400-411.

25 Plopper CG, Cranz DL, Kemp L, et al. Immunohistochemical demonstration of cytochrome P-450 monooxygenase in Clara cells throughout the tracheobronchial airways of the rabbit. Exp Lung Res 1987; 13: 59-68.

26 Van Winkle LS, Johnson ZA, Nishio SJ, et al. Early events in naphthalene-induced acute Clara cell toxicity: comparison of membrane permeability and ultrastructure. Am J Respir Cell Mol Biol 1999; 21: 44-53.

27 Kim DK, Cho MH, Hersh CP, et al. Genome-wide association analysis of blood biomarkers in chronic obstructive pulmonary disease. Am J Respir Crit Care Med 2012; 186: 1238-1247.

28 Buro-Auriemma LJ, Salit J, Hackett NR, et al. Cigarette smoking induces small airway epithelial epigenetic changes with corresponding modulation of gene expression. Hum Mol Genet 2013; 22: 4726-4738.

29 Johansson S, Andersson K, Wennergren G, et al. CC16 inhibits the migration of eosinophils towards the formyl peptide FMLF but not towards PGD2. Inflammation 2009; 32: 65-69.

30 Zhang Z, Kim SJ, Chowdhury B, et al. Interaction of uteroglobin with lipocalin-1 receptor suppresses cancer cell motility and invasion. Gene 2006; 369: 66-71.

31 Burmeister R, Boe IM, Nykjaer A, et al. A two-receptor pathway for catabolism of Clara cell secretory protein in the kidney. J Biol Chem 2001; 276: 13295-13301. 
32 Snyder JC, Reynolds SD, Hollingsworth JW, et al. Clara cells attenuate the inflammatory response through regulation of macrophage behavior. Am J Respir Cell Mol Biol 2010; 42: 161-171.

33 Pniewska E, Pawliczak R. The involvement of phospholipases A2 in asthma and chronic obstructive pulmonary disease. Mediators Inflamm 2013; 2013: 793505.

34 Churg A, Zhou S, Wang X, et al. The role of interleukin-1beta in murine cigarette smoke-induced emphysema and small airway remodeling. Am J Respir Cell Mol Biol 2009; 40: 482-490.

35 Churg A, Marshall CV, Sin DD, et al. Late intervention with a myeloperoxidase inhibitor stops progression of experimental chronic obstructive pulmonary disease. Am J Respir Crit Care Med 2012; 185: 34-43.

36 Churg A, Wang R, Wang X, et al. Effect of an MMP-9/MMP-12 inhibitor on smoke-induced emphysema and airway remodelling in Guinea pigs. Thorax 2007; 62: 706-713.

37 Reynolds SD, Mango GW, Gelein R, et al. Normal function and lack of fibronectin accumulation in kidneys of Clara cell secretory protein/uteroglobin deficient mice. Am J Kidney Dis 1999; 33: 541-551.

38 Zheng F, Kundu GC, Zhang Z, et al. Uteroglobin is essential in preventing immunoglobulin A nephropathy in mice. Nat Med 1999; 5: 1018-1025.

39 Zhang Z, Kundu GC, Yuan CJ, et al. Severe fibronectin-deposit renal glomerular disease in mice lacking uteroglobin. Science 1997; 276: 1408-1412.

40 Hagen G, Wolf M, Katyal SL, et al. Tissue-specific expression, hormonal regulation and 5'-flanking gene region of the rat Clara cell 10 KDa protein: comparison to rabbit uteroglobin. Nucleic Acids Res 1990; 18: 2939-2946. 